\title{
BMJ Open How do healthcare professionals working in accountable care organisations understand patient activation and engagement? Qualitative interviews across two time points
}

\author{
Manish K Mishra, ${ }^{1,2}$ Catherine H Saunders, ${ }^{1}$ Hector P Rodriguez, ${ }^{3}$ \\ Stephen M Shortell, ${ }^{3}$ Elliott Fisher, ${ }^{1,2}$ Glyn Elwyn ${ }^{1,2}$
}

To cite: Mishra MK, Saunders $\mathrm{CH}$, Rodriguez HP, et al. How do healthcare professionals working in accountable care organisations understand patient activation and engagement? Qualitative interviews across two time points. BMJ Open 2018;8:e023068. doi:10.1136/ bmjopen-2018-023068

- Prepublication history and additional material for this paper are available online. To view, please visit the journal (http:// dx.doi.org/10.1136/bmjopen2018-023068).

Received 21 March 2018

Revised 3 July 2018

Accepted 24 September 2018

Check for updates

(c) Author(s) (or their employer(s)) 2018. Re-use permitted under CC BY-NC. No commercial re-use. See rights and permissions. Published by BMJ.

${ }^{1}$ The Dartmouth Institute of Health Policy and Clinical

Practice, Lebanon, New

Hampshire, USA

${ }^{2}$ Geisel School of Medicine at Dartmouth, Hanover, New Hampshire, USA

${ }^{3}$ Berkeley School of Public Health, University of California, Berkeley, California, USA

Correspondence to

Dr Glyn Elwyn;

glynelwyn@gmail.com

\section{ABSTRACT}

Objective If patient engagement is the new 'blockbuster drug' why are we not seeing spectacular effects? Studies have shown that activated patients have improved health outcomes, and patient engagement has become an integral component of value-based payment and delivery models, including accountable care organisations (ACO). Yet the extent to which clinicians and managers at ACOS understand and reliably execute patient engagement in clinical encounters remains unknown. We assessed the use and understanding of patient engagement approaches among frontline clinicians and managers at ACO-affiliated practices.

Design Qualitative study; 103 in-depth, semi-structured interviews.

Participants Sixty clinicians and eight managers were interviewed at two established ACOs.

Approach We interviewed healthcare professionals about their awareness, attitudes, understanding and experiences of implementing three key approaches to patient engagement and activation: 1) goal-setting, 2) motivational interviewing and 3) shared decision making. Of the 60 clinicians, 33 were interviewed twice leading to 93 clinician interviews. Of the 8 managers, 2 were interviewed twice leading to 10 manager interviews. We used a thematic analysis approach to the data.

Key results Interviewees recognised the term 'patient activation and engagement' and had favourable attitudes about the utility of the associated skills. However, in-depth probing revealed that although interviewees reported that they used these patient activation and engagement approaches, they have limited understanding of these approaches.

Conclusions Without understanding the concept of patient activation and the associated approaches of shared decision making and motivational interviewing, effective implementation in routine care seems like a distant goal. Clinical teams in the ACO model would benefit from specificity defining key terms pertaining to the principles of patient activation and engagement. Measuring the degree of understanding with reward that are betteraligned for behaviour change will minimise the notion that these techniques are already being used and help fulfil the potential of patient-centred care.
Strengths and limitations of this study

- Significant quantity of interviews $(n=103)$ with primary care health professionals who reported on common conditions such as type II diabetes mellitus and cardiovascular disease.

- Interviews were conducted with the same teams, often the same individuals, on two separate occasions.

- Accountable care organisations were selected to represent settings that were likely to be at the cutting edge of implementing patient activation and engagement.

- Established qualitative analysis methods were used; however, not all interviews were double-coded.

- The interview data were not verified with independent observational data.

\section{INTRODUCTION}

Meaningful patient activation and engagement (PAE) is essential for achieving highquality, patient-centred care $^{1-4}$ There is wide acceptance that activated and engaged patients and families are more likely to manage their health effectively and have improved health outcomes at reduced costs. $^{3-9}$ Critical PAE approaches include goal-setting, motivational interviewing and shared decision making (SDM) (see box 1 for definitions).$^{710-12}$ These approaches have been prominent in recent healthcare policy developments, perhaps most notably in the Medicare Access and CHIP Reauthorization ACT (MACRA) legislation. ${ }^{13}$

Yet to competently implement PAE in clinical care, physicians and others must understand the underlying concepts and specific approaches involved. Research on the understanding of these concepts and the ability to implement them is scarce. Researchers have not examined how specific PAE approaches, 
Box 1 Accepted definitions of patient activation and engagement skills

Goal-setting: 'collaborative goal-setting for health behaviour change is a process by which caregiver and patient agree on a health-related goal'. 10

Motivational interviewing: a technique 'using a guiding style to engage with patients, clarify their strengths and aspirations, evoke their own motivations for change and promote autonomy of decision making'. ${ }^{11}$

Shared decision making: a technique 'where clinicians and patients make decisions together using the best available evidence, where patients are encouraged to consider available screening, treatment or management options and the likely benefits and harms of each'. Patients' preferences and values inform decision making. ${ }^{12}$

like goal-setting, motivational interviewing and SDM are understood or embedded in new care delivery and payment models. One type of new payment model, the accountable care organisations (ACO), is considered leader in patient engagement. In 2015, Shortell et al surveyed ACO leaders about PAE activities at their organisations. ${ }^{14}$ Respondents indicated that $48 \%$ of primary care providers are trained in PAE techniques and $45 \%$ use decision aids, tools that help patients compare treatment or management options, with patients and families. ${ }^{14}$ Additionally, they found nearly $60 \%$ of primary care providers have training specifically in SDM and $62 \%$ actively set goals with patients. ${ }^{14}$ Interviewees also mentioned using motivational interviewing techniques in response to open-ended questions. ${ }^{14}$ However, the survey did not assess understanding or execution of these PAE techniques. ${ }^{14}$ The extent to which clinicians and managers at ACOs understand and deploy PAE skills in clinical encounters is unknown.

To address this gap, we conducted a two-phase, cross-sectional qualitative study to assess the use and understanding of PAE approaches among frontline clinicians and managers at ACO-affiliated practices. Although several methods exist to enhance PAE, we focused on assessing the extent that members of the recruited teams were aware of, understood and implemented three critical PAE skills: goal-setting, motivational interviewing and SDM.

\section{METHODS}

\section{Patient and public involvement}

Two patients participated in the study's scientific advisory committee panel.

\section{Setting and participants}

The ACOs we studied were the DaVita HealthCare Partners (DHCP) organisation in Los Angeles and the Advocate Healthcare organisation in Chicago. We chose ACOs because of their reputation for undertaking patient engagement activities and therefore would provide insights on how other settings might be working. We visited eight practice sites associated with each ACO; locations ranged from medical centres in metropolitan areas to rural community-based clinics.

\section{Recruitment and approach}

We assessed levels of PAE in the 71 primary care sites of the two selected ACOs using a 39-item survey instrument (see online supplementary appendix 1) administered in the 6-month period before each cycle of site visits. Clinical site leaders selected frontline staff for interviews and an office or similar was made available at each setting. Only the interviewers and interviewees were present.

\section{Data collection}

We conducted interviews during a 1-week period in May 2015 and in May 2016. We spent 2 days at each ACO and visited 16 practice sites. Interviewers included up to seven clinicians and social scientists, depending on the site. After obtaining consent, each interview was recorded and subsequently transcribed. Interviews averaged 1 hour each.

Based on the literature, prior experience and the advice of a scientific advisory committee, we developed a semi-structured interview guide focused on PAE activities, with question prompts that focused on type II diabetes mellitus and cardiovascular disease, and specifically on the interviewee's understanding of PAE and barriers to implementation. Between the first and second interview cycles, we added additional questions about PAE techniques for engagement (see online supplementary appendix 2 ). We also provided a summary of the finding to the leadership of practice in the gap between interview cycles.

\section{Data analysis}

We used an inductive thematic approach to analyse the interview data ${ }^{15}$ to identify recurrent themes relating to our PAE focus: goal-setting, motivational interviewing and SDM. Data analysis had three overlapping and iterative stages. ${ }^{16}$ In the first stage, CHS coded the text 'lineby-line' using ATLAS.ti software. ${ }^{17}$ Second, MM checked a $10 \%$ sample for comparison, selecting randomly from the data set. Both researchers organised the codes into a $\operatorname{codebook}^{17}$ (see online supplementary appendix 3 ). In the third stage, both CHS and MM reviewed the data and derived unifying analytical themes to summarise the findings. ${ }^{17}$ These themes were not determined ahead of time. The primary researcher reviewed each transcript at least two times, adapting codes and adding memos to indicate potential themes. The core team for this analysis (CHS, MM and GE), met every 2 weeks to discuss emerging themes and confirm data saturation, ${ }^{18}$ paying attention to theme-contradicting data. We did not explicitly compare the responses of different professional disciplines. Consoldiated Criteria for Reporting Qualitative Research (COREQ) qualitative research reporting standards were used to guide the presentation of this work (see online supplementary appendix 4). 
Table 1 Professional roles and location of participants

\begin{tabular}{lllcccc}
\hline Site & Interview cycle & $\begin{array}{l}\text { Medical } \\
\text { assistant }\end{array}$ & Nurse & $\begin{array}{l}\text { Nurse } \\
\text { practitioner }\end{array}$ & Physician & Management \\
\hline Chicago & T1 & 6 & 10 & 1 & 8 & 1 \\
& T2 & 6 & 9 & 0 & 9 & 4 \\
Los Angeles & T1 & 7 & 10 & 0 & 8 & 2 \\
\multirow{2}{*}{ Total } & T2 & 6 & 7 & 0 & 6 & 3 \\
\hline
\end{tabular}

\section{Research team and reflexivity}

Personal characteristics

\section{Interviewers}

Twelve individuals conducted interviews. The group consisted of healthcare services researchers and clinicians (SB, GE, EF, VH, SI, KM, MM, PR, DR, HR, SSsee online supplementary appendix 5 ).

\section{Relationship with participants}

We established relationships with clinical leaders prior to site visits and data collection. We told the participants that we were researchers from TDI and UCB studying the role of PAE in ACO healthcare models.

\section{RESULTS}

The research team conducted 103 interviews with 68 professionals (table 1). The team members interviewed included physicians, nurses, medical assistants and, in some cases, diabetic nurse educators, social workers and site administrators. When we compared interview in the first and second interview cycles, we did not discern thematic differences. Coders had been blinded to the identity of clinics, and no thematic differences were detected between these categories of clinics.

\section{Themes}

During thematic analysis, four dominant themes emerged: (1) participants recognised and were well aware of PAE terminology; (2) participants had positive appraisals of these PAE approaches; (3) participants had limited understanding of specific PAE techniques, including goal-setting, motivational interviewing and SDM; (4) participants reported or acknowledged partial implementation of PAE approaches (figure 1).

\section{Recognition}

Most interviewees in both cycles recognised and were aware of patient activation, patient engagement and associated terms. Some interviewees were more familiar with the concepts than others and could accurately describe the core principles. A doctor, for instance, characterised his understanding of the term 'PAE' below:

It means that the patient is being more of a participant in their own care and not just being a passive observer, and me telling them what to do. They're actively engaging and really trying to learn more about their disease and to do something more with that disease process. (Primary care physician (11015P))

Most respondents reported that their colleagues at their clinics and organisations understood PAE concepts. A nurse, for instance, used words like 'we' and 'us' to signal an assumed shared understanding of PAE:

It's very important that our patients are engaged, meaning that they are involved, because, again, we need to know what's going on with them in order for us to make the best decisions together. And to get them to want to improve. So, it's 100 percent across the board. (Nurse (11031N))

The interviewees also recognised specific PAE skills. A primary care physician (21009P) said confidently, "I'm aware of the concepts (of PAE and SDM)". A nurse $(11010 \mathrm{~N})$ said, "I know about motivational interviewing". And a member of the management team at one ACO (11008M) said, "we do try to drive that... (ie, goal setting)". As a whole, interviewee responses indicated that these terms were familiar to the participants. Most but not all interviewees were comfortable answering questions about PAE concepts and skills.

\section{Positive appraisal}

Participants expressed almost universally positive attitudes towards PAE. In a representative response about PAE generally, one nurse (11017N) said, "I think (it is) extremely important. We need patients to be engaged and willing to want to help out with their own care and willing to acquire knowledge of their own [...] their medical conditions". Her response indicates her own appreciation for the role of PAE in keeping patients healthy. Similarly, a clinical manager $(11008 \mathrm{M})$ said '(PAE is) absolutely critical', indicating that the leadership, in addition to frontline staff, thought that PAE was important to their organisation.

Respondents also shared positive perceptions of specific PAE techniques. In response to a question about the use of decision aids, one doctor (11004P) said that using them, 'would be a good thing' indicating appreciation for their value. After a question about motivational interviewing, a nurse (21013N), said, "I think they're very good ideas", and noted that although these patient-engagement techniques are not used often, "I think it might be a very, very good thing to try, absolutely". This 
Recognition

Appraisal

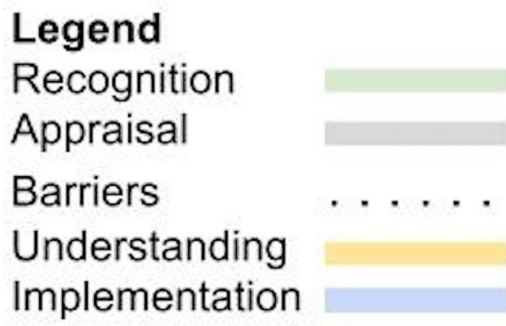

response indicates positive feelings about motivational interviewing while acknowledging that the approach is an aspiration rather than a reality. Concerning goal-setting, a member of the management team $(11027 \mathrm{M})$ at one ACO said, "I would love for (what matters most to patients) to be captured because that changes the whole equation. If somebody wants to stay alive till their son graduates, then figuring that out is (critical)". As with other interviewees, responses indicated positive attitudes yet at the same time an open admission that the approaches were not being actively adopted.

\section{Limited understanding}

Despite recognition and positive attitudes, participants understanding of specific PAE techniques was limited. We compared participants' responses to accepted definitions, detailed in figure 1 . Some were clear about their unfamiliarity. One nurse (21004N) said, "I don't know what you mean by (goal setting)". This same nurse (21004N) had confidently answered a question about PAE earlier in the interview, saying it is, "patient participation, knowing, knowledge, their ability to want to participate'.

Many interviewees described PAE techniques in ways that did not align with accepted definitions. As an example, after a question about whether her clinic used tools or forms for goal-setting or SDM, one medical assistant (11023A) said, "I use an Accu machine to check patients' blood sugar levels". This response indicates a belief that monitoring clinical indicators was equivalent to goal-setting. Others believed goal-setting was about assigning both behavioural and clinical targets to patients, without collaboration:

I make sure that I sort of hold them accountable. I say 'okay, well, we're going to put down a goal here. I'm going to write it in the chart that we want to lose this amount of weight, or we're going to exercise, or you're saying that you're going to do this activity, and so in a month I'd like to see you back in here with your food diary or your sugar monitoring'. (Primary care physician (11005P))

Another thematic misunderstanding was equating goal setting to history taking and physical exam. As an example, one medical assistant (21028A) answered a question about goal setting by saying, "when they come in, (we need) their physical (examination), a historysome of the patients never had an EKG. [...] so you can discuss your problems that you're having. [...] So I make little notes of it...". 
Similarly, clinicians frequently cited using encouragement or adopting good interpersonal skills as evidence of motivational interviewing. One medical assistant (11009A) said, "I'm a good listener from what I hear. Sometimes people just need an ear. They don't need any, anything else, right?" Interviewees were not familiar with the core ideas, or terms used, by professionals who are skilled at motivational interviewing.

Clinicians also responded to questions about patient decision aids by giving information about general patient education materials or brochures, indicating that they did not understand the distinction between patient information and patient-facing tools designed to help patients understand trade-offs when comparing treatment options. When asked about patient decision aids one nurse $(21010 \mathrm{~N})$ said, "We use booklets. We use visual aids. We use handouts and just hands-on teaching, like teaching (the) glucometer. We do a lot of teaching of (the) glucometer, teaching how to check your sugars, teaching how to do the medications". Several nurses and medical assistants responded to questions about patient decision aids with assurance that they use the informational printouts from resources such as UpToDate. Physicians also made the mistake of equating patient decision aids with printed After-Visit Summaries.

Clinicians also responded with comments about the work they did to achieve biomedically determined quality measures and targets, such as optimal control of blood pressure and blood glucose levels. Asked about efforts in his clinic to encourage patient participation, one physician (11015P) said, "We're trying to make sure that we hit the meaningful use (targets), so we try and print the patient education (materials) right after every visit". Asked about collaborative goal-setting with patients, that same physician (11015P) said, "[I] talk to them and inform them, that's our goal for the patients", indicating goals are viewed as the patients' achieving set population targets, rather than engaging with patients to determine goals that are driven by their own priorities. Clinicians expressed frustration that externally set targets acted to drive their practice and that external targets over-ruled any effort to place emphasis on patient-centred priorities.

\section{Partial implementation}

Because participants had limited understanding of PAE concepts, it followed that evidence of PAE implementation in routine clinical practice was limited. Participants readily confirmed that the implementation of PAE techniques was partial. When we asked one member of the management team $(21018 \mathrm{M})$, for instance, if the ACO worked to prioritise collaborative goal-setting with patients, the response was, "No. I really-I guess I really should-it's just that it doesn't happen", and this admission represented a widespread acknowledgement that PAE was essentially aspirational. In a few cases, interviews with members of the management teams attested that PAE activities did take place, but interviews with frontline clinicians did not confirm their assertions. When we asked a doctor (21009P) about use of motivational interviewing in routine care, we received this response, "I'm aware of the concept, ... we haven't had these things implemented in this clinic". This pattern was evident across all the interview data related to all three PAE techniques: goal-setting, motivational interviewing and SDM.

Commonly cited barriers to PAE were the low levels of administrative support and lack of sufficient time. Of note, there was no mention of lack of understanding or training in PAE techniques as a barrier. As an example, a manager (21019M) at one of the ACOs said the feasibility of implementing a motivational interviewing programme was limited until they had more staff support, "I think before we could really go down the path of doing more around motivational interviewing, we're going to have to (adjust staff levels)". Similarly, a physician (21029P) said there was no time to follow-up with patients about goals in a routine fashion. "I guess I really should... it's just that it doesn't happen. I don't have the time to follow back up with some of those patients to see if they've really met their goals".

Some clinicians assumed their colleagues were already trained in, and routinely employing, these skills. Asked about whether training was available for SDM and motivational interviewing, one doctor shared a comment that implied an assumption that his colleagues, by virtue of day to day practice, were already competent in PAE approaches.

I'm not aware of any formal training, but on the other hand, all of us have - of course, all of us went to medical school, and all of us went through the medical residencies. I have four physicians in this clinic. Every single one of my physicians has been practicing medicine for over 10 years. And I do believe that we have a lot of practical skills. (Primary care physician (21008P))

Similarly, there was a lack of clarity about who was responsible for PAE activities, a sense that it was important and that it was a task that had to be done by others. When asked about who sets collaborative goals with patients, a nurse $(21003 \mathrm{~N})$ suggested her colleagues might be doing it, "I let them talk to the dietician and she encourages them. And I'm sure the doctor does too, (but) like I said, I just don't follow-up on them per se".

Although the ACOs did not implement most PAE techniques, we did find evidence that both organisations have integrated the Five Wishes advance directive into their work flow for patients older than 65 years. ${ }^{19}$ The Five Wishes form has SDM elements and its routine use represents a partial implementation of SDM at these ACOs.

\section{DISCUSSION}

\section{Principal findings}

We found consistent evidence that health professionals and ACO leadership were aware of patient engagement concepts such as goal setting, motivational interviewing 
and SDM. They reported having favourable regard and support of these approaches to patient care. Despite the positive inclinations, we found consistent evidence of misunderstanding and misinterpretation. There was agreement that PAE was a 'good thing'; but beyond a superficial endorsement, we found no evidence that PAE approaches were being adopted into routine care. In fact, we found evidence that PAE techniques were often understood as expedient ways to meet externally driven, biomedical targets.

We found deep misunderstandings of PAE principles in the two studied ACOs, which are widely considered to be leaders in adopting these approaches. These misunderstandings are even more likely in care settings that do not espouse to be among the leading proponents of PAE. Perceptions that PAE is already happening lead to perpetuation of the status quo. That leads to a lack of motivation to do more, negates the need for further training and minimises the potential power of PAE. They are not seeing the effects or reaping the benefits.

Our findings also underscore the pervasive influence of incentivised performance targets at ACOs. Incentives were reported as being significant factors in leading clinicians to encourage, if not direct, patients to achieve suggested levels of blood pressure and blood sugar. The incentives to achieve biomedical targets, however, do not encourage collaborative goal-setting, negotiated behaviour changes or jointly made decisions.

\section{Strengths and limitations}

Conducting the study in two well-established ACOs committed to enhancing their PAE activities is a strength of our study. The selection of established ACOs increases the likelihood that our findings are applicable beyond these organisations. There is no evidence to suggest that other ACOs would have more advanced PAE activities. We acknowledge that generalising beyond the ACOs we studied and to primary care clinics overall carries risk, given that there are over 800 ACOs in the USA, all at different stages of maturity. ${ }^{20}$

A second strength is the number of interviews conducted (103), with a wide range of primary care team members over two rounds. Interviewing the same participants twice gave us the opportunity to assess potential change over time.

Data analysis followed established qualitative methods, using a coding process that two researchers developed collaboratively. We acknowledge that the absence of double-independent coding across all the data is a potential weakness of our approach; a second researcher coded $10 \%$ of the transcripts for validation.

A weakness is the absence of independent observational data to verify our conclusions. Although we interviewed a significant sample, we accept that social desirability could have influenced the interviewee responses and may have led respondents to react more positively to the PAE questions. ${ }^{2122} \mathrm{~A}$ wish to portray the organisation in a positive light, coupled with fear of workplace repercussions are relevant factors for qualitative data collected by face-toface interviews. Other limitations include the difficulty to account for the variation in training for the PAE techniques that we focused on. Additionally, formal theory was not used in the data analysis and the demographic data for the interviewees were omitted. Also, the study was conducted in the USA and results may not directly be generalisable to other healthcare contexts.

\section{Results in context}

Few other studies have examined the views of health professionals about PAE approaches. Alvarez et al found variations in primary care providers' attitudes about PAE. ${ }^{23}$ Shortell $e t$ al, in a prior study assessing the landscape of PAE at ACOs, ${ }^{14}$ found, "efforts are underway (at ACOs) to engage patients and their families through multiple means'. Our study suggests an important disconnect between leaders' beliefs and frontline care delivery. Although clinicians and managers in these ACOs reported that they used the specific approaches we studied in their clinical practices, in-depth semi-structured interviews revealed low levels of understanding and implementation. This mismatch of perceived high levels of confidence coupled with low levels of accurate interpretation and implementation is similar to what has been called the Dunning-Kruger effect. This effect is a phenomenon, whereby people with low comprehension and ability tend to overestimate their proficiency in a given task. ${ }^{24}$

The ACOs' efforts to encourage patients to change behaviour to meet known (and incentivised) biomedical goals appear to be incompatible with PAE approaches, as described in the literature. Emphasis on clinical targets, such as blood pressure or sugar levels, smoking cessation or lipid control as targets of PAE, were prominent in our findings. Other studies have found similar tensions between patient-centred care and population-driven metrics. ${ }^{25}{ }^{26}$ Research on other pay-for-performance arrangements suggest these models can positively influence 'incentivised clinical processes', but whether they improve patient experiences or even lead to adversarial relationships is unknown. ${ }^{25}{ }^{27}$ The accounts of frustration that we heard during our interviews run the risk that Wainwright $e t$ al identified of professionals 'failing to interact with patients as whole persons with unique expertise on their bodies, their experience of illness and their lives'. ${ }^{27}$

Barriers to implementation of novel concepts or innovations in routine clinical care have been explored in detail. ${ }^{28-32}$ In a narrative review, Nilsen et al collated implementation science theories and summarised their ideas. In aggregate, they found the theories supported the idea that knowledge predicts the formation of attitudes, which in turn, shapes behaviours. ${ }^{30}$ Our interpretation of barriers to implementation differs from this model because we think it is important to parse understanding from knowledge, resistance from attitudes and motivations from behaviours. The cornerstone of our argument is the difference between awareness and comprehension. Knowledge of the PAE concepts was widespread in our 
interviews, but comprehension-of the extent required to enact the approaches-was largely absent. With these theories in mind, we assert that lack of a full understanding of PAE techniques and implementation requirements is a significant barrier to routine use in primary care practices.

\section{Implications}

Partnership between patients and clinicians is the underpinning principle of PAE, ${ }^{33} 34$ where the definitions of goal setting, motivational interviewing and SDM make it clear that the respect for the underlying wishes and priorities of the patient should be the foundation of practice. At the core of PAE is respect for patients' autonomy, provided they are made aware of their situation. In this study, we found evidence that PAE is not viewed in this way, but rather it is interpreted as pressing patients to meet incentivised biomedical targets. In our view, this interpretation sets the stage for conflict, frustration and professional burnout. Just as importantly, incentivised targets can lead to patient disengagement and disenchantment. If PAE is improperly or partially captured by a value-based compensation model, it comes at the risk of being at odds with delivering patient-centred care. Future approaches should prioritise engagement in high-quality co-production and communication with patients. ${ }^{33}$ This is consistent with recent research indicating that physicians' desire to provide better care for patients is more motivating than their desire for financial rewards. ${ }^{35}$ As we have reported in this study, incentives will inevitably drive practice patterns and influence the emphasis of patient engagement approaches. We have also shown, there is a relationship between understanding and implementing PAE into clinical care. One approach we suggest is to measure the degree of implementation of PAE techniques, as a surrogate for understanding and reward clinicians who score high on metrics such as patient-reported health outcome measures. If the incentives are better aligned with desirable behaviour change, we will likely see the PAE model achieve its full potential. The move away from fee-for-service towards payment for value is an important and significant development. Yet, as we show here, there is more progress to be made towards turning the 'rhetoric of patient-centred care into reality' ${ }^{36}$ If healthcare organisations wish to optimise patient-centred care, we suggest they move beyond a superficial understanding of PAE.

Acknowledgements The authors acknowledge Pamela Bagley's guidance in designing literature searches for this study. The authors want to thank Robin Paradis Montibello and Lisa Sharp Grady for their assistance with manuscript preparation. The authors acknowledge and thank the following individuals who participated as site visit interviewers (in addition to several coauthors) or who helped to arrange the site visits and provided feedback reports to the sites: Salma Bibi, Thomas Huber, Susan Ivey, Zosha Kandel, Kathy McDonald, Patricia Ramsay and Diane Rittenhouse.

Contributors The conception of the study and the design of the work: SMS, HPR, EF. Acquisition of data: SMS, HPR, MKM, GE, EF. Thematic analysis of data, interpretation of the data, drafting of manuscript: MKM, CHS, GE. Critical revision, editing of manuscript and contribution to intellectual content and approval of all aspects of the final manuscript: MKM, GE, CHS, SMS, HPR, EF.
Funding This research was supported by the Patient-Centred Outcomes Research Institute (PCORI) (grant: IHS-1310-06821). The views, statements, opinions presented in this work are solely the responsibility of the authors and do not necessarily represent the views of the Patient-Centered Outcomes Research Institute (PCORI), its Board of Governors, or Methodology Committee. This work was also supported in part by AHRQ's Comparative Health System Performance Initiative under grant \# 1U19HS024075, which studies how healthcare delivery systems promote evidence-based practices and patient-centred outcomes research in delivering care.

Competing interests GE has been a consultant to Emmi Solutions, which develops patient decision support tools; National Quality Forum on certification of decision support tools; Washington State Health Department on certification of decision support tools; PatientWisdom; SciMentum, Amsterdam and Access Community Health Network, Chicago. He has edited/published books that provide royalties on sales by the publishers: the books include SDM (0xford University Press) and Groups (Radcliffe Press). He also initiated and leads the Option Grid patient decision aids collaborative, which produces and publishes patient knowledge tools in the form of comparison tables (http://optiongrid.org) and has part ownership of the registered trademark. He owns a copyright in CollaboRATE, IntegRATE and Observer OPTION measures of SDM and care integration. These measures are freely available for use. EF reports personal fees from Christiana Care Health System, personal fees from American College of Pathologists, personal fees from Angiodynamics (for profit company), personal fees from Blue Cross, Blue Shield of LA, personal fees from National Confederation of General Insurance, Private Pension and Life, Supplementary Health and Capitalization Companies, Brazil, personal fees from Blue Cross, Blue Shield of South Carolina, personal fees from Vizient, personal fees from Signature Healthcare Foundation, grants from Commonwealth Fund, grants from Agency for Healthcare Research and Quality, outside the submitted work; and he is a member of the Board of Directors of the Institute for Healthcare Improvement and the Fannie E Rippel Foundation.

\section{Patient consent Not required.}

Ethics approval This study was approved by the Institutional Review Board of The University of California, Berkeley School of Public Health (UCB) and The Dartmouth Institute for Health Policy and Clinical Practice (TDI).

Provenance and peer review Not commissioned; externally peer reviewed.

Data sharing statement There are no additional data to share.

Open access This is an open access article distributed in accordance with the Creative Commons Attribution Non Commercial (CC BY-NC 4.0) license, which permits others to distribute, remix, adapt, build upon this work non-commercially, and license their derivative works on different terms, provided the original work is properly cited, appropriate credit is given, any changes made indicated, and the use is non-commercial. See: http://creativecommons.org/licenses/by-nc/4.0/.

\section{REFERENCES}

1. Joseph-Williams N, Lloyd A, Edwards A, et al. Implementing shared decision making in the NHS: lessons from the MAGIC programme. BMJ 2017;357:j1744.

2. Dentzer S. Rx for the 'Blockbuster Drug' of patient engagement. Health Aff 2013;32:202.

3. Hibbard JH, Greene J. What the evidence shows about patient activation: better health outcomes and care experiences; fewer data on costs. Health Aff 2013;32:207-14.

4. Hibbard JH, Greene J, Overton V. Patients with lower activation associated with higher costs; delivery systems should know their patients' 'scores'. Health Aff 2013;32:216-22.

5. Greene J, Hibbard JH. Why does patient activation matter? An examination of the relationships between patient activation and health-related outcomes. J Gen Intern Med 2012;27:520-6.

6. Street RL, Makoul G, Arora NK, et al. How does communication heal? Pathways linking clinician-patient communication to health outcomes. Patient Educ Couns 2009;74:295-301.

7. Bodenheimer T, Lorig K, Holman $\mathrm{H}$, et al. Patient self-management of chronic disease in primary care. JAMA 2002;288:2469-75.

8. Stewart MA, Ma S, Stewart MA. Effective physician-patient communication and health outcomes: a review. CMAJ 1995;152:1423-33.

9. Fireman B, Bartlett J, Selby J. Can disease management reduce health care costs by improving quality? Health Aff 2004;23:63-75.

10. Bodenheimer T, Handley MA. Goal-setting for behavior change in primary care: an exploration and status report. Patient Educ Couns 2009;76:174-80. 
11. Rollnick S, Butler CC, Kinnersley P, et al. Motivational interviewing. BMJ 2010;340:c1900.

12. Elwyn G, Frosch D, Volandes $A E$, et al. Investing in deliberation: a definition and classification of decision support interventions for people facing difficult health decisions. Med Decis Making 2010;30:701-11.

13 Clough JD, McClellan M. Implementing MACRA: implications for physicians and for physician leadership. JAMA 2016;315:2397-8.

14. Shortell SM, Sehgal NJ, Bibi S, et al. An early assessment of accountable care organizations' efforts to engage patients and their families. Med Care Res Rev 2015;72:580-604.

15. Braun V, Clarke V. Using thematic analysis in psychology. Qual Res Psychol 2006;3:77-101.

16. Pope C, Ziebland S, Mays N, et al. Qualitative research in health care. 3rd edn. Oxford, UK: Blackwell Publishing Ltd, 2007:63-81.

17. Pope C, Mays N. Reaching the parts other methods cannot reach: an introduction to qualitative methods in health and health services research. BMJ 1995;311:42-5.

18. Boeije H. A purposeful approach to the constant comparative method in the analysis of qualitative interviews. Quality and Quantity 2002;36:391-409.

19. Wenger B, Asakura $Y$, Fink RM, et al. Dissemination of the five wishes advance directive at work. J Hosp Palliat Nurs 2012;14:551-8.

20. Colla $\mathrm{CH}$, Lewis VA, Tierney E, et al. Hospitals participating In ACOs tend to be large and urban, allowing access to capital and data. Health Aff 2016;35:431-9.

21. Fisher RJ. Social desirability bias and the validity of indirect questioning. J Consum Res 1993;20:303.

22. Kuper A, Lingard L, Levinson W. Critically appraising qualitative research. BMJ 2008;337:a1035-9.

23. Alvarez C, Greene J, Hibbard J, et al. The role of primary care providers in patient activation and engagement in self-management: a cross-sectional analysis. BMC Health Serv Res 2016;16:85.

24. Kruger J, Dunning D. Unskilled and unaware of it: how difficulties in recognizing one's own incompetence lead to inflated self-assessments. J Pers Soc Psychol 1999;77:1121-34.

25. Peckham TJ. 'Doctor, have I got a fracture or a break'? Injury 1994;25:221-2

26. Roland M, Olesen F. Can pay for performance improve the quality of primary care? BMJ 2016;354:i4058.

27. Wainwright D, Donovan JL, Kavadas V, et al. Remapping the body: learning to eat again after surgery for esophageal cancer. Qual Health Res 2007;17:759-71.

28. Elwyn G, Scholl I, Tietbohl C, et al. "Many miles to go ...": a systematic review of the implementation of patient decision support interventions into routine clinical practice. BMC Med Inform Decis Mak 2013;13(Suppl 2):S14.

29. May C, Finch T. Implementing, embedding, and Integrating practices: an outline of normalization process theory. Sociology 2009;43:535-54.

30. Nilsen P. Making sense of implementation theories, models and frameworks. Implement Sci 2015;10:53.

31. Damschroder LJ, Aron DC, Keith RE, et al. Fostering implementation of health services research findings into practice: a consolidated framework for advancing implementation science. Implement Sci 2009;4:50.

32. Cochrane LJ, Olson CA, Murray S, et al. Gaps between knowing and doing: understanding and assessing the barriers to optimal health care. J Contin Educ Health Prof 2007;27:94-102.

33. Batalden M, Batalden $\mathrm{P}$, Margolis $\mathrm{P}$, et al. Coproduction of healthcare service. BMJ Qual Saf 2016;25:509-17.

34. Gilardi S, Guglielmetti C, Marsilio M, et al. Co-production in healthcare: moving patient engagement towards a managerial approach: Springer International Publishing, 2016:77-95.

35. Phipps-Taylor M, Shortell SM. More than money: motivating physician behavior change in accountable care organizations. Milbank Q 2016;94:832-61.

36. Barry MJ, Edgman-Levitan S. Shared decision making--pinnacle of patient-centered care. N Engl J Med 2012;366:780-1. 